\title{
Crystal structure of bis(dimethylsulfoxide) dinitrato dioxo uranium(VI), $\mathrm{UO}_{2}\left(\mathrm{NO}_{3}\right)_{2}\left[\left(\mathrm{CH}_{3}\right)_{2} \mathrm{SO}\right]_{2}$
}

\author{
M. Saßmannshausen ${ }^{\text {I }}$ H. D. Lutz ${ }^{*, I}$ and A. Zazhogin ${ }^{11}$ \\ ${ }^{1}$ Universität-GH Siegen, Anorganische Chemie I, D-57068 Siegen, Germany \\ II Laser Physics and Spectroscopy Department, F. Skorina av. 4, 220080 Minsk, Belarus
}

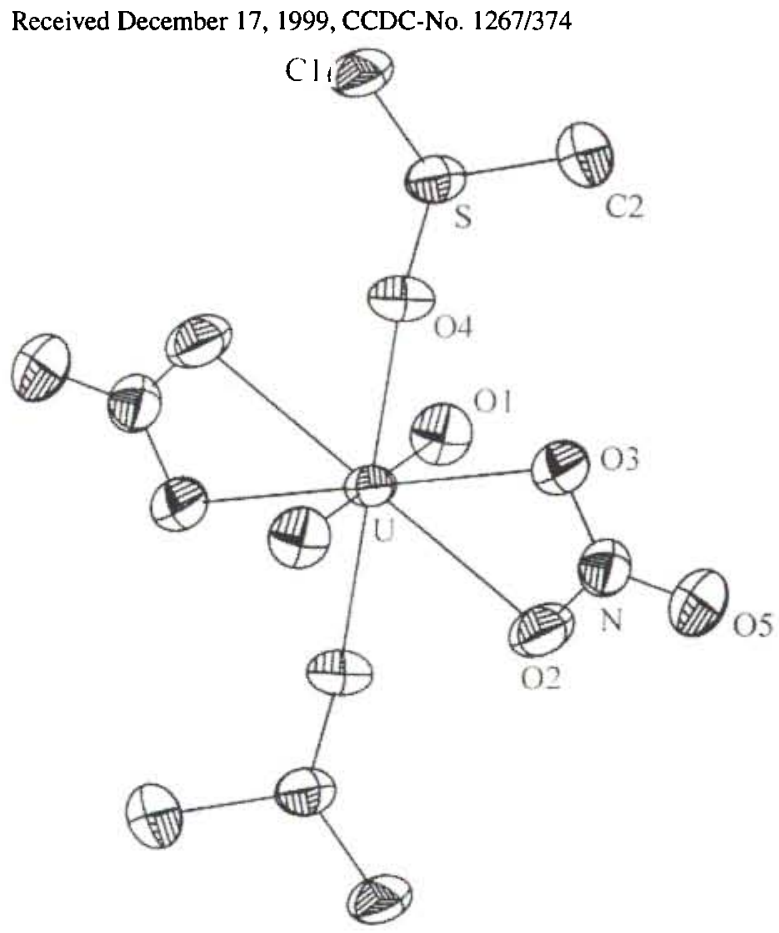

\author{
Abstract \\ $\mathrm{C}_{4} \mathrm{H}_{12} \mathrm{~N}_{2} \mathrm{O}_{10} \mathrm{~S}_{2} \mathrm{U}$, monoclinic, $C 12 / c \mathrm{l}$ (No. 15), $a=17.781(8) \AA$, \\ $b=5.974(3) \AA, c=15.361(8) \AA, \beta=117.78(4)^{\circ}$, \\ $V=1443.7 \AA^{3}, Z=4, R_{\mathrm{gt}}(F)=0.036, w R_{\mathrm{ref}}\left(F^{2}\right)=0.086$, \\ $T=293 \mathrm{~K}$
}

\section{Source of material}

Single crystals were prepared by solving a stoichiometric mixture of uranyl nitrate hexahydrate and dimethyl sulfoxide in diethyl ether. Within one day the compound crystallizes. The crystals are filtered off and dried at air.

\section{Experimental details}

Because of the presence of uranium presence of uranium atoms sătisfactory refinement of th ehydrigen positions was not possible.

\begin{abstract}
Discussion
In the monoclinic structure, the uranium atoms are at the centrosymmetric $4 c$ sites being coordinated by eight oxygen atoms. The two $\mathrm{O}$ atoms of the linear uranyl group are nearly perpendicularly orientated to the plane of the remaining $\mathrm{O}$ atoms forming a hexagonal bipyramid around the uranium atom. Altogether the hexagon is composed of four oxygen atoms of the two equivalent bidentate nitrate groups and two oxygen atoms of the equivalent dimethyl sulfoxide molecules. The bond lengths and angles in the dimethyl sulfoxide group are in good agreement with average values for $\mathrm{O}$ bonded uranium and other metal sulfoxides [1] and with vibrational frequencies of the $\mathrm{UO}_{2}{ }^{2+}$ unit in relation to Gutman's donor numbers [2]. The $\mathrm{U}-\mathrm{O}\left(\mathrm{UO}_{2}{ }^{2+}\right)$ distances $(1.744(7) \AA)$, however, are too crude in order to reflect the change of the strength of the $\mathrm{U}-\mathrm{O}$ bonds. The shortest intermolecular $\mathrm{C} \cdots \mathrm{O}$ distances are $\mathrm{C} 1$ to $\mathrm{O} 5(\mathrm{Cl} \cdots \mathrm{O} 53.36(3) \AA)$ and $\mathrm{C} 2$ to $\mathrm{O} 4(\mathrm{C} 2 \cdots \mathrm{O} 43.35(3) \AA)$. Therefore weak $\mathrm{C}-\mathrm{H} \cdots \mathrm{O}$ hydrogen bonds [3] to the $\mathrm{NO}_{3}{ }^{-}$ligands $(\mathrm{O} 5)$ and the sulfoxide group (O4) must be taken in consideration despite the very weak hydrogen bond acceptor capability of $\mathrm{NO}_{3}{ }^{-}$ions [4]. The co-ordination of $\mathrm{O}$ bonded metal ions in sulfoxides can be stereochemically defined by the torsion angles $\psi_{1}$ (M-O-S-Cl) and $\psi_{2}\left(\mathrm{M}-\mathrm{O}-\mathrm{S}-\mathrm{C}_{2}\right)$ [1]. For the title compound, $\psi_{1}$ is $-147.2(5)^{\circ}$ and $\psi_{2}$ is $109.9(6)^{\circ}$ showing a trans-trans conformation.
\end{abstract}

Table 1. Data collection and handling.

\section{Crystal:}

Wavelength:

$\mu$ :

Diffractometer, scan mode: $2 \theta_{\text {Irax: }}$ :

$N(h k l)_{\text {measured, }} N(h k l)_{\text {unique: }}$

Criterion for $I_{\mathrm{obs}}, N(h k l)_{\mathrm{gt}}$ : $N(\text { param })_{\text {refined: }}$ Programs: light yellow prism, size $0.08 \times 0.10 \times 0.20 \mathrm{~mm}$ Mo $K_{\alpha}$ radiation $(0.71069 \AA$ ) $115.77 \mathrm{~cm}^{-1}$

Enraf-Nonius CAD4, $\omega$ $49.92^{\circ}$

4774,1265

$I_{\text {obs }}>2 \sigma\left(I_{\text {obs }}\right), 893$

89

SHELXS-86 [5], SHELXL-93 [6] ATOMS [7]

\footnotetext{
* Correspondence author (e-mail: lutz@chemie.uni-siegen.de)
} 
Table 2. Atomic coordinates and displacement parameters (in $\AA^{2}$ ).

\begin{tabular}{|c|c|c|c|c|c|c|c|c|c|c|}
\hline Atom & Site & $x$ & $y$ & $z$ & $U_{11}$ & $U_{22}$ & $U_{33}$ & $U_{12}$ & $U_{13}$ & $U_{23}$ \\
\hline $\mathbf{U}$ & $4 c$ & $1 / 4$ & $1 / 4$ & 0 & $0.0283(3)$ & $0.0334(3)$ & $0.0241(3)$ & $-0.0031(2)$ & $0.0073(2)$ & $-0.0005(2)$ \\
\hline$O(1)$ & $8 f$ & $0.1974(4)$ & $0.023(1)$ & $0.0184(5)$ & $0.034(3)$ & $0.047(4)$ & $0.055(4)$ & $-0.006(3)$ & $0.027(3)$ & $0.003(4)$ \\
\hline $\mathrm{O}(2)$ & $8 f$ & $0.1114(4)$ & $0.444(1)$ & $-0.1072(5)$ & $0.043(4)$ & $0.070(5)$ & $0.034(4)$ & $0.012(4)$ & $0.008(3)$ & $0.001(4)$ \\
\hline$O(3)$ & $8 f$ & $0.1589(4)$ & $0.500(1)$ & $0.0462(5)$ & $0.051(4)$ & $0.053(4)$ & $0.038(4)$ & $0.013(4)$ & $0.009(3)$ & $-0.003(4)$ \\
\hline$O(4)$ & $8 f$ & $0.3090(4)$ & $0.342(1)$ & $0.1681(5)$ & $0.038(4)$ & $0.054(4)$ & $0.032(4)$ & $-0.008(3)$ & $0.010(3)$ & $-0.008(3)$ \\
\hline$O(5)$ & $8 f$ & $0.0396(5)$ & $0.652(2)$ & $-0.0577(7)$ & $0.042(5)$ & $0.062(5)$ & $0.074(6)$ & $0.017(4)$ & $0.015(4)$ & $-0.003(5)$ \\
\hline $\mathrm{S}$ & $8 f$ & $0.3838(2)$ & $0.4983(5)$ & $0.2294(2)$ & $0.032(1)$ & $0.050(1)$ & $0.033(1)$ & $-0.002(1)$ & $0.0113(9)$ & $-0.004(1)$ \\
\hline $\mathbf{N}$ & $8 f$ & $0.1009(5)$ & $0.539(1)$ & $-0.0406(7)$ & $0.040(5)$ & $0.036(5)$ & $0.049(6)$ & $0.002(4)$ & $0.015(4)$ & $0.002(4)$ \\
\hline$C(1)$ & $8 f$ & $0.4312(8)$ & $0.372(2)$ & $0.3480(9)$ & $0.068(8)$ & $0.043(7)$ & $0.040(7)$ & $0.001(6)$ & $-0.013(6)$ & $0.008(5)$ \\
\hline $\mathrm{C}(2)$ & $8 f$ & $0.3345(9)$ & $0.731(2)$ & $0.254(1)$ & $0.061(8)$ & $0.051(7)$ & $0.064(8)$ & $0.011(5)$ & $0.021(7)$ & $-0.014(6)$ \\
\hline
\end{tabular}

\section{References}

1. Calligaris, M.; Carugo, O.: Structure and bonding in metal sulfoxide complexes. Coord. Chem. Rev. 153 (1996) 83-154.

2. Zazhogin, A. A.; Lutz, H. D.; Komyak, A. I.: Influence of the neutral ligands donicity on the vibrational spectra of uranyl nitrates. I. Internal vibrational modes. J. Mol. Struct. 483 (1999) 189-193.

3. Steiner, Th.: Unrolling the hydrogen bond properties of $\mathrm{C}-\mathrm{H} \cdots \mathrm{O}$ interactions. Chem. Comm. (1997) 727-734.
4. Lutz, H. D.: Hydroxide Ions in Condensed Materials - Correlation of Spectroscopic and Structural Data. Struct. Bonding 82 (1995) 85-103.

5. Sheldrick, G. M.: SHELXS-86. Program for the Solution of Crystal Structures. University of Göttingen, Germany 1985.

6. Sheldrick, G. M.: SHELXL-93. Program for the Refinement of Crystal Structures, University of Göttingen, Germany 1993.

7. Dowty, E.: ATOMS. A Computer Program for Displaying Atomic Structures. Version 3.1 for Windows. Hidden Valley Road, Kingsport, TN 37663, USA 1995. 